Thorax (1975) 30, 399.

\title{
A pulmonary hypertension-producing plant from Tanzania
}

\author{
D O NALD HEATH, JAMES SHABA, \\ A N D R W WILLIAMS, PAULSMITH, \\ and A L I K O M B E \\ The Departments of Pathology, Universities of Liverpool and Dar-es-Salaam
}

\begin{abstract}
Heath, D., Shaba, J., Williams, A., Smith, P., and Kombe, A. (1975). Thorax, 30, 399-404. A pulmonary hypertension-producing plant from Tanzania. An African youth who had died from primary pulmonary hypertension was suspected of having ingesied a herbal remedy containing the seeds of the local plant Crotalaria laburnoides. Consequently powdered seeds of this plant were fed to 20 Wistar albino rats for 60 days to see if this would induce ventricular hypertrophy and associated hypertensive pulmonary vascular disease. At the end of the experimental period right ventricular hypertrophy, medial hypertrophy of the pulmonary trunk and 'muscular pulmonary arteries', and muscularization of the pulmonary arterioles had developed in a proportion of the test animals. These are the morbid anatomical features pathognomonic of a raised pulmonary arterial pressure and show that the seeds of Crotalaria laburnoides contain an agent capable of inducing pulmonary hypertension in rats. This study suggests the value of seeking a history of ingestion of herbal remedies and drugs in cases of unexplained pulmonary hypertension in man.
\end{abstract}

On a recent visit to Tanzania one of the authors (D.H.) was shown histological sections of lung from a youth of 19 years who had died in congestive cardiac failure. Pulmonary histopathology included angiomatoid lesions, and since this boy did not have any congenital cardiac septal defect, bilharzial infection or any cause of portal hypertension (all conditions which may give rise to such lesions), it was considered to be consistent with primary pulmonary hypertension. This patient came from Kilwa, an area where witch doctors still practise, administering herbal concoctions to their customers. It is well known that certain plants, when ingested, may induce hypertension and associated vascular disease in the pulmonary circulation. The plants so far incriminated are Crotalaria spectabilis (Kay and Heath, 1966), C. fulva (Kay et al., 1971), and Senecio jacobaea (Burns, 1972). In the event we were unable to establish that this boy had been given any herbal infusion containing one of the many species of Crotalaria growing in the area where he lived. The seeds of one of these, $C$. laburnoides, when fed to rats, induced right ventricular hypertrophy and hypertensive pulmonary vascular disease.

\section{MATERIAL AND METHODS}

Crotalaria laburnoides is a leguminous plant of widespread distribution in East Africa occurring in Tanzania, Kenya, and Uganda. It is sometimes called $C$. bagamoyoënsis since it grows in the coastal area around the small township of Bagamoyo which was an important centre of the African slave trade in the last century. David Livingstone knew this town and was almost certainly familiar with the plant which forms the subject of this communication.

C. laburnoides grows in the bush in sand dunes and coral outcrops near the coast, and less commonly at lakesides inland. It is an erect annual, up to $7 \mathrm{dm}$ tall and much branched, particularly towards the base, and has trifoliate leaves with elliptic-lanceolate leaflets. It bears racemes, up to 6 to $18 \mathrm{~cm}$ long, the individual flowers being yellow finely veined with red. They have the characteristic form of flowers of the Leguminoseae with prominent wings and a keel. The pods occur in groups (Fig. 1) and contain 16 to 28 seeds. The seeds are cordiform, smooth, shiny, and light tan in colour. 


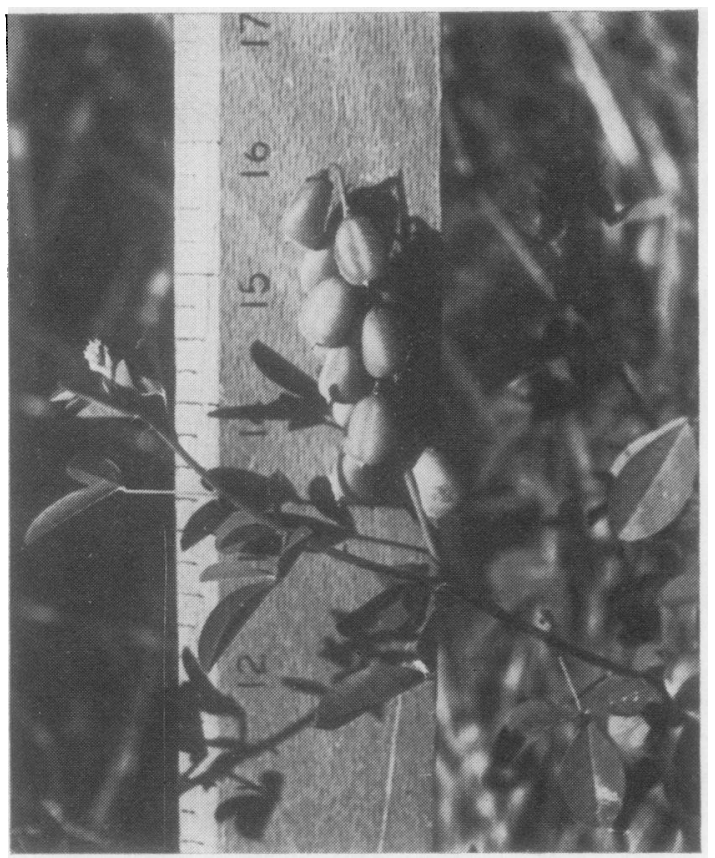

FIG. 1. Crotalaria laburnoides growing in its natural habitat in the bush near the coast of Tanzania. Note the characteristic seed-pods.

Twenty-four Wistar albino rats weighing between 110 and $210 \mathrm{~g}$ were divided into 20 test rats (T1-T20) and four controls (C1-C4). We used a small number of controls because in previous studies (Kay and Heath, 1966; Heath and Kay, 1967) we had established from much larger series of controls the normal ranges for the $\mathrm{LV}+\mathrm{S} / \mathrm{RV}$ and $\mathrm{PT} / \mathrm{A}$ ratios and the percentage medial thickness of the muscular pulmonary arteries that we have studied in this investigation. The control values that we have found in the present small series agree with those that we established in the more extensive previous studies. The control animals were housed singly and were fed on powdered rat cubes and given free access to water. The test rats were housed singly and their diet was adulterated by powdered seeds of C. laburnoides. In rats $\mathrm{T} 1$ to $\mathrm{T} 10$ the seed powder was added to give a concentration of $2 \mathrm{~g}$ per $\mathrm{kg}$ diet $(0.2 \%$ by weight). In rats $\mathrm{T} 11$ to $\mathrm{T} 20$ the concentration of the seed powder in the diet was $0.4 \%$ by weight. The rats were weighed weekly. They were killed with ether vapour on the sixtieth day of the experiment. Rat T17 died spontaneously on the fifty-fifth day and was excluded from the experiment.

At necropsy the thorax was opened and the thoracic viscera were removed. The lungs were $\overrightarrow{\vec{s}}$ distended through the trachea with $4 \%$ formaldehyde in normal saline until the pleural surfaces $\underline{0}$ were smooth. At this stage the heart was kept $\frac{\bar{\rho}}{\bar{b}}$ attached to the lungs, and the thoracic viscera $\mathbb{\otimes}$ were immersed in the same solution until fixation was complete.

After fixation the heart was dissected by the $\vec{\circ}$ method of Fulton, Hutchinson, and Morgan $\overrightarrow{\vec{\omega}}$ Jones (1952) and the weight of the free wall of the $\stackrel{\omega}{\omega}$ right ventricle was expressed as an inverse ratio $\overrightarrow{\vec{x}}$ of the combined weight of the left ventricle and $\underset{\omega}{x}$ interventricular septum $(\mathrm{LV}+\mathrm{S} / \mathrm{RV}$ ratio). This is a sensitive method of detecting right ventricular $\vec{\omega}$ hypertrophy. On histological sections of the pul- $\mathbb{E}$ monary trunk, aorta, and lungs other measure-응 ments were made to detect morbid anatomical $\vec{?}$ evidence of pulmonary arterial hypertension. The $>$ mean medial thickness of the pulmonary trunke् was expressed as a ratio of that of the aorta (PT/ $\frac{\infty}{\omega}$ A ratio), as we have described previously (Heath $\overrightarrow{\vec{\theta}}$ and Kay, 1967). The medial thickness of the 'muscular pulmonary arteries' was expressed as a percentage of the external diameter of the walls (MT\%) by the method described in our earlier studies (Kay and Heath, 1966).

\section{RESULTS}

QUALITATIVE DATA The histological appearances $\overline{\overline{ }}$ of the pulmonary trunk and aorta in control and test animals are illustrated in Figures 2 and 3. The changes in the test animals were identical with those found in rats fed on $C$. spectabilis seeds and reported previously (Heath and Kay, 1967).

Small pulmonary arterial vessels in control animals $\stackrel{\times}{\circ}$ The muscular pulmonary arteries of the control 3 . rats had a very thin media of circularly orientated smooth muscle sandwiched between internal and₹ external elastic laminae (Fig. 4). There was noo form of intimal proliferation. The pulmonary arterioles had a wall consisting of a single elastico lamina as in the human lung.

Small pulmonary arterial vessels in test animals. showing right ventricular hypertrophy The mus- 0 cular pulmonary arteries of those test rats whichN had developed right ventricular hypertrophyo showed medial hypertrophy associated with crenaro tion of the internal elastic lamina suggestive of constriction (Fig. 5). In these animals there was $\stackrel{?}{+}$ no form of intimal proliferation. There were not dilatation lesions and there was no necrotizing $\stackrel{\vec{D}}{\vec{D}}$ arteritis.

In striking contrast to those of the controls, the pulmonary arterioles of the test rats showing rightog 


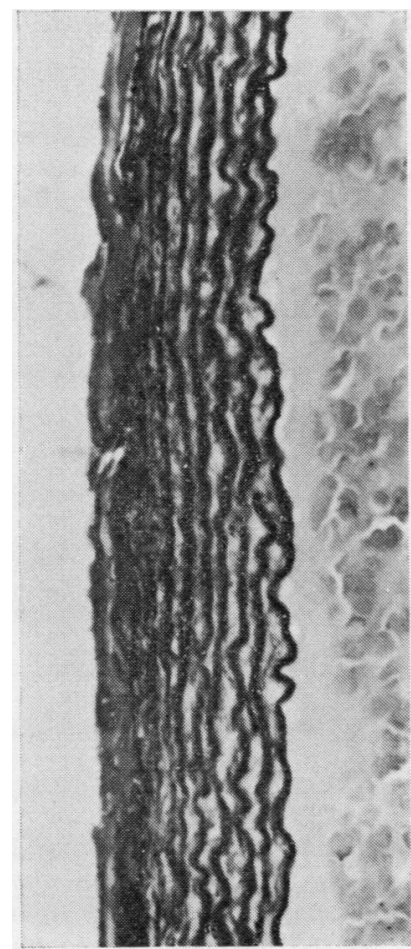

FIG. 2. Part of transverse section of the pulmonary trunk from one of the control rats. The media is thin and contains long, parallel elastic fibres packed tightly together. The adventitia is to the left. The PT/A ratio was 0.30. Compare these appearances with those in the test animal shown in Fig. 3. (Elastic van Gieson $\times 360$ )

ventricular hypertrophy were muscularized and resembled systemic arterioles. In Fig. 6 such a muscularized pulmonary arteriole is shown deliberately at a low magnification to demonstrate how muscularization had affected even the smallest radicles of the pulmonary arterial tree. In Fig. 7 this muscularized arteriole is shown at much higher magnification to demonstrate its structure. A coat of muscle has formed internally to the original single thick elastic lamina of the arteriole and a much thinner new single elastic lamina now lines the inner surface of this new muscle coat. It was considered that such appearances were more likely to result from hyperplasia of new muscle in the pulmonary arterioles than from constriction of muscular pulmonary arteries.

QUANTITATIVE DATA (FIGS 8 To 10 ) In the control rats the ratio of the medial thickness of the pulmonary trunk to that of the aorta ranged from 0.29 to 0.40 , and the mean PT/A ratio was 0.36 .

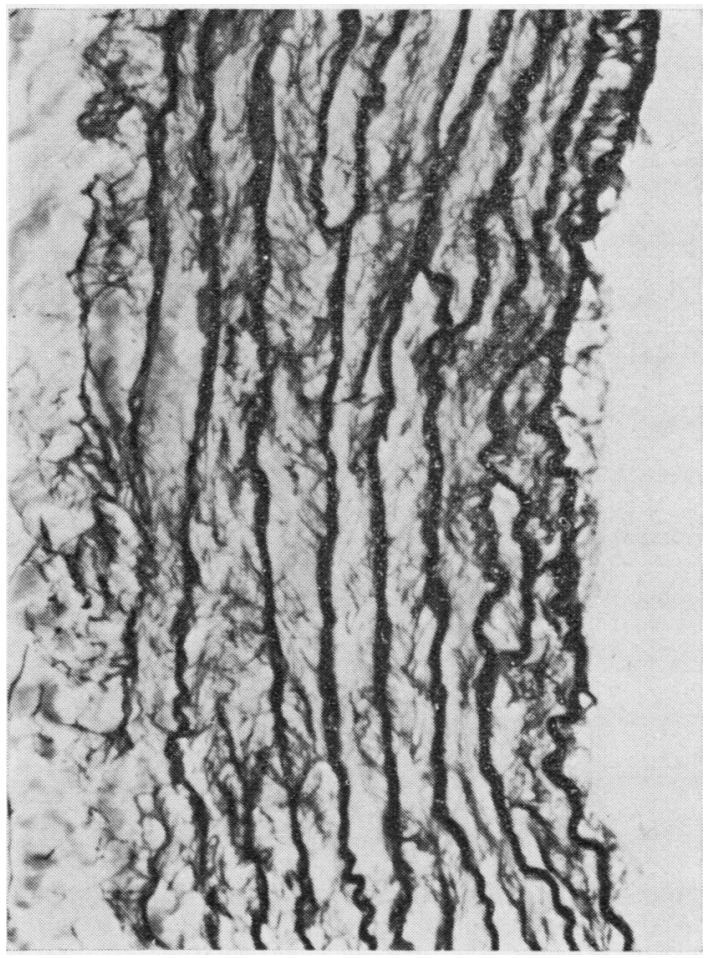

FIG. 3. Part of transverse section of the pulmonary trunk from one of the test rats with right ventricular hypertrophy taken at the same magnification as the control pulmonary trunk shown in Fig. 2. The media is hypertrophied and the elastic fibres are separated by the hyperplastic smooth muscle. The PT/A ratio was 0.92 . $(E V G \times 360)$

The average medial thickness of the small pulmonary arteries ranged from 3.0 to $4.0 \%$ and the mean value was $3.5 \%$. The ratio of the combined weight of the left ventricle and interventricular septum to that of the right ventricle $(\mathrm{LV}+\mathrm{S} / \mathrm{RV}$ ratio) ranged from 3.1 to 4.0 with a mean value of 3.5 .

In the test rats the $\mathrm{PT} / \mathrm{A}$ ratio ranged from 0.39 to 0.95 and the mean ratio was 0.63 . The average medial thickness of the small pulmonary arteries ranged from 4.0 to $10.0 \%$ and the mean value was $7.0 \%$. The $\mathrm{LV}+\mathrm{S} / \mathrm{RV}$ ratio ranged from 1.5 to 5.0 with a mean value of 2.9 .

The results showed that in the test rats there was a fall in the $L V+S / R V$ ratio, indicating the development of right ventricular hypertrophy. In some animals this ratio fell as low as 1.5 , indicating a severe degree of right ventricular hypertrophy. There was an increase in the PT/A ratio, and in some animals the pulmonary trunk was 


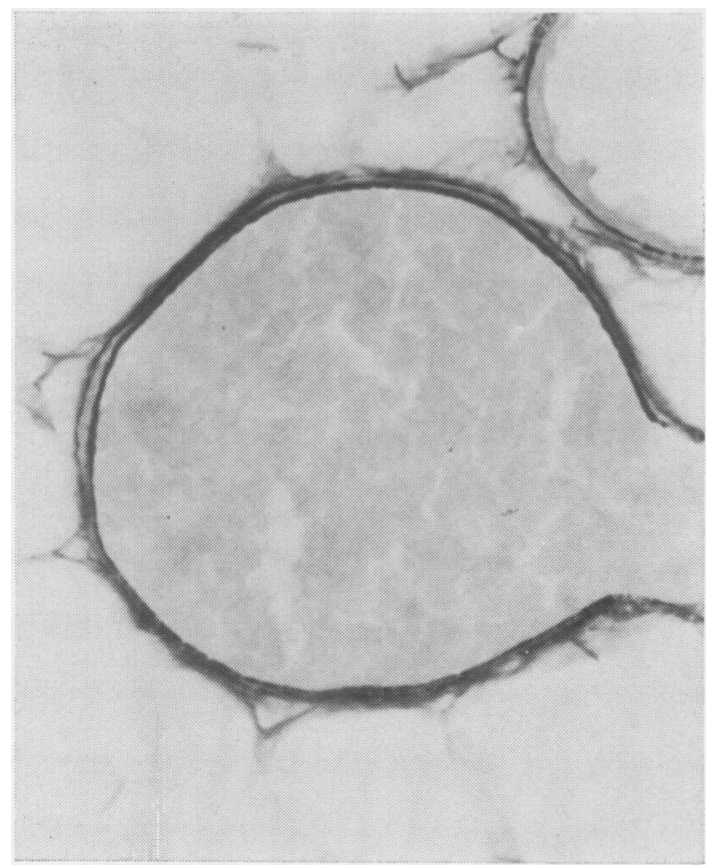

FIG. 4. Transverse section of a muscular pulmonary artery from one of the control rats. It has a very thin media sandwiched between internal and external elastic laminae. $(E V G \times 528)$

almost as thick as the aorta. The medial thickness of the muscular pulmonary arteries increased and in some of the test rats rose to $10 \%$, indicating pronounced medial hypertrophy.

The relation of the $L V+S / R V$ ratio to the $\mathrm{PT} / \mathrm{A}$ ratio is shown in Figure 8. The relation of the $\mathrm{LV}+\mathrm{S} / \mathrm{RV}$ ratio to the percentage medial thickness of the small pulmonary arteries is shown in Figure 9. The relation of the PT/A ratio to the percentage medial thickness of the small pulmonary arteries is shown in Figure 10. In general, as the $\mathrm{LV}+\mathrm{S} / \mathrm{RV}$ ratio fell there was an increase in the $\mathrm{PT} / \mathrm{A}$ ratio and the percentage medial thickness of muscular pulmonary arteries.

Total body weight in test and control rats The test rats fed on the seeds gained weight less rapidly than the controls. The average weight gain for the test rats during the experimental period was $27 \mathrm{~g}$ and for the control animals $109 \mathrm{~g}$.

\section{DISCUSSION}

Our study has shown that a proportion of rats ingesting the seeds of $C$. laburnoides develop right ventricular hypertrophy, medial hypertrophy of the pulmonary trunk, increased medial thickness

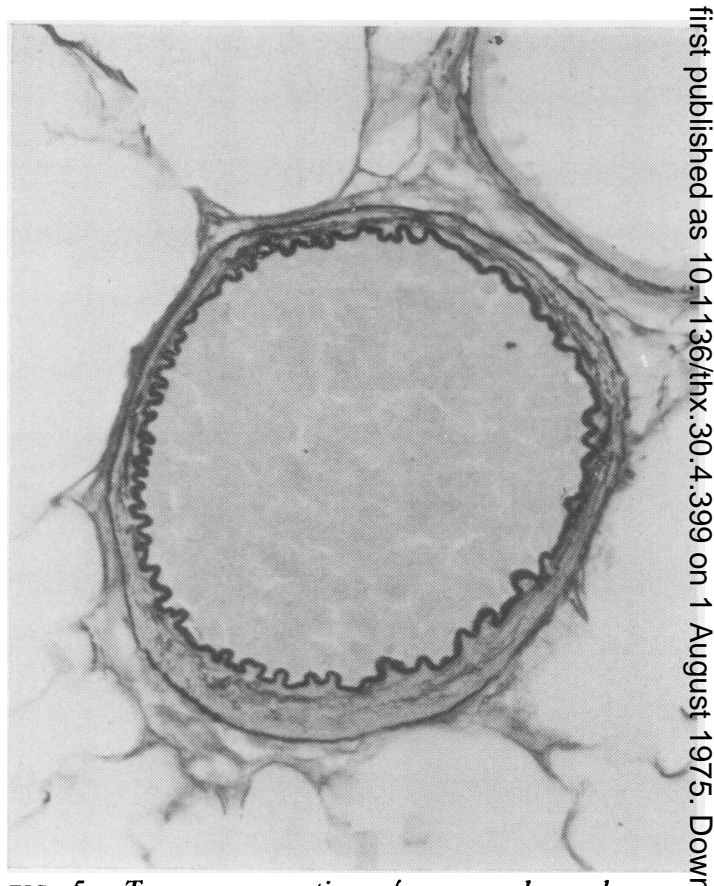

FIG. 5. Transverse section of a muscular pulmonar artery from one of the test rats with right ventriculow hypertrophy. There is medial hypertrophy with creno tion of the internal elastic lamina suggestive of vaso constriction. In this case the $L V+S / R V$ ratio wa 2.2. $(E V G \times 360)$

of the muscular pulmonary arteries, and muscula rization of the pulmonary arterioles. These are the morbid anatomical features pathognomonic of raised pulmonary arterial pressure, and the development indicates that the seeds of this Afr? can plant contain an agent capable of elevating pulmonary vascular resistance. Previous studies i⿱日 our laboratory on the production of pulmonary hypertension and associated vascular lesions io the lungs of animals by feeding them on extracts of certain plant substances showed that the active. agents were pyrrolizidine alkaloids. On this basis it is likely that the active agent in the seeds of C. laburnoides capable of producing pulmonar: hypertension in rats is also a pyrrolizidine alkaloids

The alkaloids that we have previously incrime nated in the production of pulmonary hypertem sion are monocrotaline from $C$. spectabilis (Kaळ and Heath, 1966), fulvine from C. fulva (Kay et al., 1971), and senecionine from Senecio jaco baea (Burns, 1972). We are not aware of an studies which have isolated the alkaloids present i\& C. laburnoides. The mechanism by which the alk $\mathbb{D}$ loid increases pulmonary vascular resistance is 


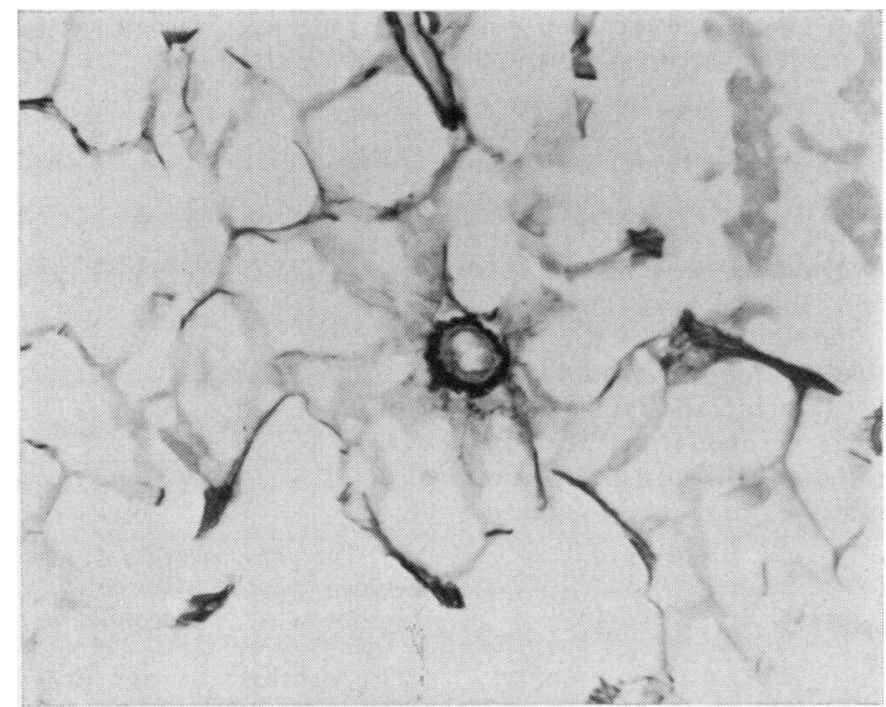

FIG. 6. Transverse section of a pulmonary arteriole from one of the test rats with right ventricular hypertrophy. Note how even the smallest radicles of the pulmonary arterial tree show muscularization. $(E V G \times 375)$

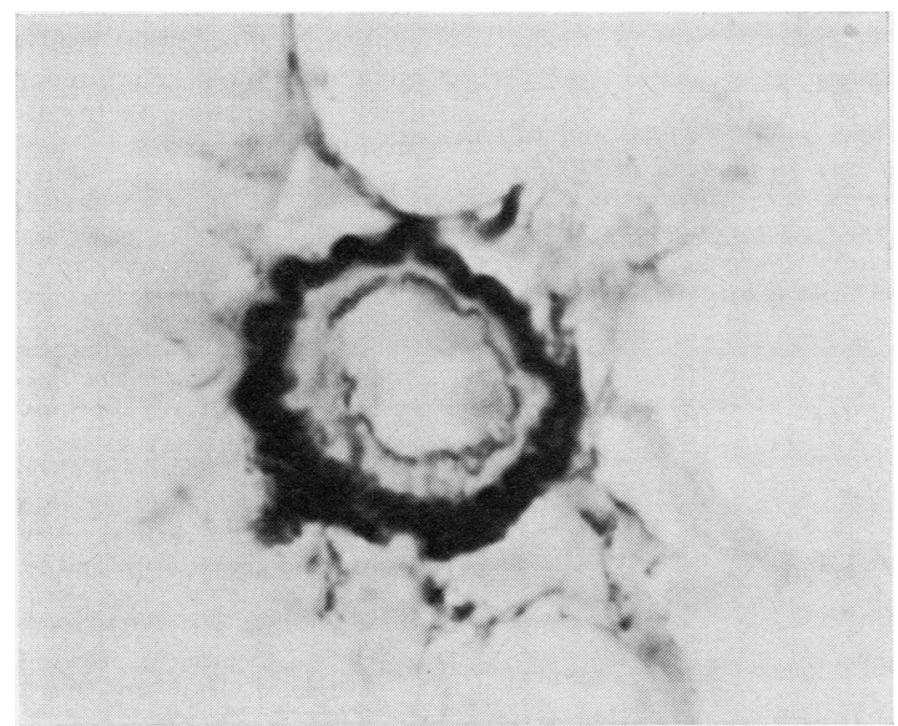

FIG. 7. Transverse section of the pulmonary arteriole shown in Fig. 6 at much higher magnification under oil immersion to show its structure. The original single thick elastic lamina of the arteriole is seen. Internal to it is a new layer of smooth muscle. This is bounded on its inner aspect by a new thin single elastic lamina. $(E V G \times 1500)$ 
likely to be muscularization of the terminal portions of the pulmonary arterial tree as illustrated in Figs 6 and 7.

Although, as stated above, we were led to the investigation of this plant by the suspicion that an African boy who had developed unexplained pulmonary hypertension had ingested a herbal mixture containing C. laburnoides, we were unable to prove this association. However, we have been able to demonstrate that the seeds of this plant will induce the morbid anatomical counterparts of pulmonary hypertension in rats. Our findings suggest that in case of unexplained ('primary') pulmonary hypertension in man a history of ingestion of drugs and herbal remedies should be sought.

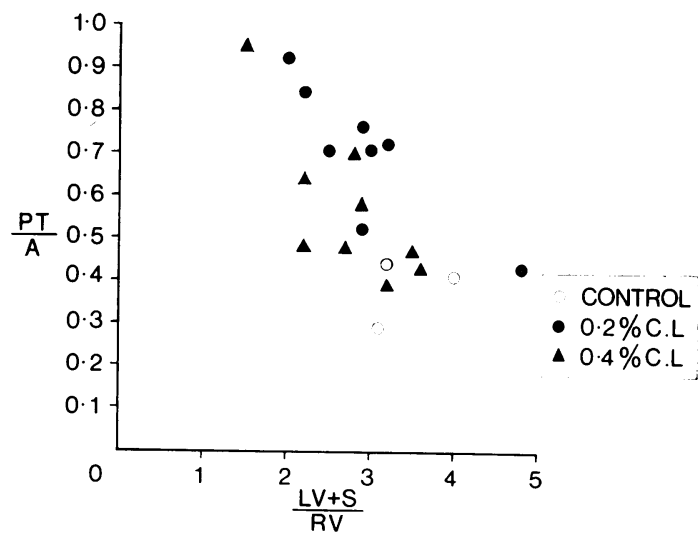

FIG. 8. The relation between $L V+S / R V$ and $P T / A$ in the control and test rats. In this and the following two figures control animals are indicated by an open circle, test rats fed on a diet containing $0.2 \% \mathrm{C}$. laburnoides seeds by closed circles, and test rats fed on a diet containing $0.4 \%$ seeds by closed triangles.

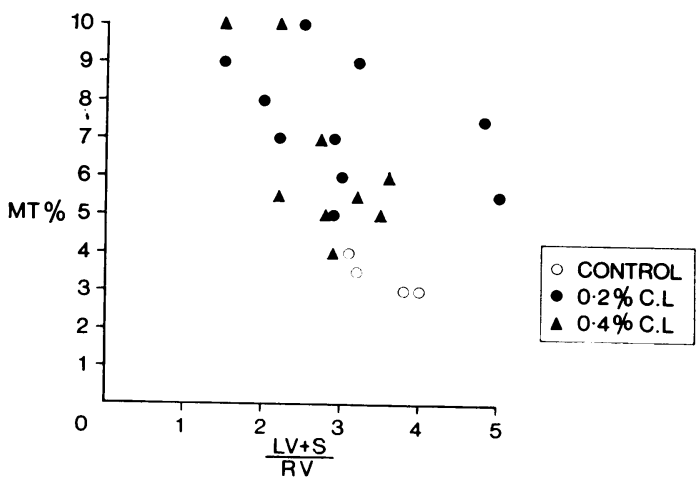

FIG. 9. The relation between $L V+S / R V$ and the percentage medial thickness of the small pulmonary arteries in test and control animals.

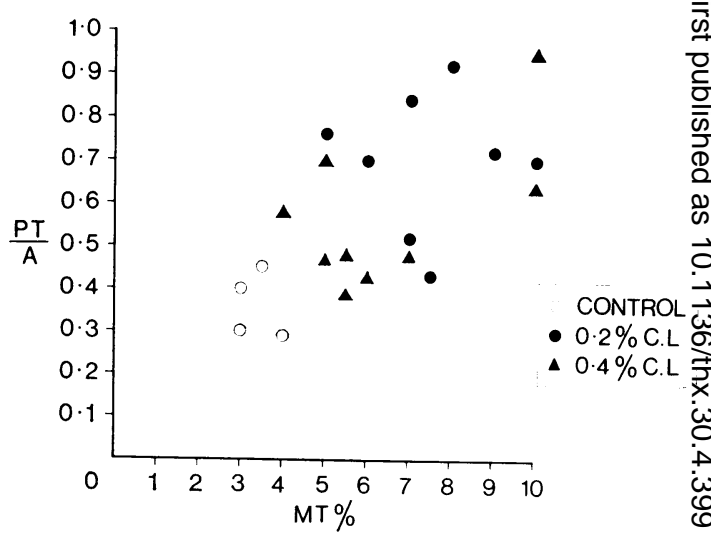

FIG. 10. The relation between $P T / A$ and the pers centage medial thickness of the small pulmonary arteries in test and control animals.

In contrast to our previous studies using $C_{0}$ spectabilis and fulvine, only a proportion of the rats fed on $C$. laburnoides seeds developed right ventricular hypertrophy and associated pulmonary vascular disease. It is possible that the alkaloids if C. laburnoides are not as potent as monocrotalin or fulvine. However, there is an alternative exo planation. When the seeds used in this study werहू gathered in Tanzania they were gathered in dank tropical conditions and were gently heated to pre $\overrightarrow{\vec{F}}$ vent the seeds rotting. This preliminary heat treat 3 ment may have denatured the alkaloids to somer extent inactivating their pulmonary hypertensione producing properties.

\section{REFERENCES}

Burns, J. (1972). The heart and pulmonary arteries i rats fed on Senecio jacobaea. Journal of Pathology, 106, 187.

Fulton, R. M., Hutchinson, E. C., and Morgan Jones A. (1952). Ventricular weight in cardiac hyper? trophy. British Heart Journal, 14, 413.

Heath, D. and Kay, J. M. (1967). Medial thickness of pulmonary trunk in rats with cor pulmonale in duced by ingestion of Crotalaria spectabilis seeds? Cardiovascular Research, 1, 74.

Kay, J. M. and Heath, D. (1966). Observations on the pulmonary arteries and heart weight of rats fed on Crotalaria spectabilis seeds. Journal of Pathology and Bacteriology, 92, 385.

,-- , Smith, P., Bras, G., and Summerell, Jर (1971). Fulvine and the pulmonary circulatione Thorax, 26, 249.

Milne-Redhead, E. and Polhill, R. M. (editors). (1971): In Flora of Tropical East Africa. Leguminoseae (Part 4), p. 966. Crown Agents for Oversea? Governments and Administrations, London.

Requests for reprints to: Professor D. Heath, Depart $\stackrel{D}{2}$ ment of Pathology, University of Liverpool L69 3BX 